\title{
NYELEHIN KAIWANGAN-KAIWANGAN WEWEHAN LAN EJAAN BASA BALI RING WACANA BUKU AJAH LATANSA AKSARA MADRASAH TSANAWIYAH
}

\author{
Rukmana Yanti ${ }^{1}$, I.A. Putu Purnami ${ }^{1}$, I. B. Putra Manik Aryana ${ }^{2}$ \\ Jurusan Pendidikan Bahasa Bali \\ Universitas Pendidikan Ganesha \\ Singaraja, Indonesia \\ e-mail: \{rukmanayanti16@gmail.com, dayupurnamiku@yahoo.com, \\ putramanikaryana@gmail.com\}@undiksha.ac.id
}

\begin{abstract}
KUUB
Tetilikan matetujon nlatarang: (1) kaiwangan-kaiwangan wewehan sane wenten ring wacana buku ajah Latansa Aksara Madrasah Tsanawiyah, (2) kaiwangankaiwangan ejaan Basa Bali sane wenten ring wacana buku ajah Latansa Aksara Madrasah Tsanawiyah. Tetilik nganggen kramaning dokumentasi ri kala mupulang data kaiwangan-kaiwangan wewehan lan kaiwangan-kaiwangan ejaan basa Bali, taler nganggen piranti kartu data rikala mupulang data sane jagi karereh. Data tureksa sane kanggen: (1) nyelehin data; (2) nyorohang data; lan (3) pangwedar data; (4) pamicutet. Pikolih tetilik kaiwangan wewehan lan ejaan basa Bali ring buku ajah Latansa Aksara Madrasah Tsanawiyah, sakadi: (1) kaiwangan wewehan, sakadi: pangater, wewehan gabungan. (2) kaiwangan ejaan basa Bali, sakadi: (1) huruf kapital, (2) huruf sendeh,(3) kruna lingga, (4) kruna tiron, (5) ceciren pepaosan.
\end{abstract}

Kruna jejaton: wewehan, ejaan, wacana buku ajah

\begin{abstract}
ABSTRAK
Penelitian ini bertujuan menjelaskan: (1) kesalahan-kesalahan afiksasi yang ada di buku ajar Latansa Aksara Madrasah Tsanawiyah; (2) kesalahan-kesalahan ejaan bahasa Bali yang ada di buku ajar Latansa Aksara Madrasah Tsanawiyah. Penelitian ini menggunakan metode dokumentasi pada saat mengumpulkan data kesalahan-kesalahan afiksasi dan kesalahan-kesalahan ejaan bahasa Bali, dan menggunakan alat berupa kartu data saat mengumpulkan data yang ingin di cari. Analisis data yang digunakan: (1) reduksi data; (2) klasifikasi data; dan (3) memaparkan data (4)kesimpulan/verifikasi. Hasil penelitian kesalahan afiksasi dan ejaan bahasa Bali di buku ajar Latansa Aksara Madrasah Tsanawiyah, seperti: (1) kesalahan afiksasi, seperti: prefiks, konfiks. (2) kesalahan ejaan bahasa Bali, seperti: (1) huruf kapital, (2) cetak miring, (3) kata dasar, (4) kata imbuhan, (5) tanda baca.
\end{abstract}

Kata kunci: afiksasi, ejaan, wacana buku ajar 


\begin{abstract}
This study aimed to explain (1) affixation errors that exist in the textbook Latansa Aksara Madrasah Tsanawiyah, (2) Balinese spelling errors in the textbook Latansa Aksara Madrasah Tsanawiyah. This research used documentation method in order to collect the data of affixation and Balinese spelling errors and used a instrument named card data to collect the findings. The data were analyzed by using (1) data reduction, (2) data classification, and (3) the data description (4) conclusion / verification. The results of this research based on the affixation and spelling errors of Balinese language in Latansa Aksara Madrasah Tsanawiyah textbooks, namely (1) affixation errors, such as prefix, confix. (2) Balinese spelling errors, such as (1) capital letters, (2) italics, (3) core words, (4) affixation, (5) mechanics.
\end{abstract}

Keywords: Affixation, Spelling, Discourse.

\section{PURWAKA}

Buku pinaka sarana sane mabuat, awinan madaging makudang-kudang gatra sane jagi kauningin. Buku silih sinunggil piranti peplajahan sane kanggen ring sekolah, nika ngawinang soangsoang sekolah sampun nyangkepin sarana perpustakaan sane prasida kanggen ri kala para sisia jagi ngwacen utawi ngrereh gatra indik widya sane kaplajahin. Buku-buku sane wenten ring perpustakaan sekolah sakadi kamus, ensiklopedi, buku satua, buku ajah miwah buku sane lianan.

Buku ajah pinaka piranti peplajahan sane mabuat pisan, santukan kantos mangkin buku ajah tetep kabaos piranti peplajahan sane mautama. Yening kacingakin saking sekolahan (institusi pendidikan) sane dasar kantos sane pinih tegeh, samian sekolah punika nganggen buku ajah pinaka piranti peplajahan sane utama. Parindikan punika nyihnayang yening kawentenan buku ajah nenten prasida lempas tekening pamargi peplajahan sane wenten ring sekolah mangkin. Buku ajah inggih punika buku sane madaging aji pangweruhan, katedunang saking kompetensi dasar sane wenten ring kurikulum taler buku punika kanggen olih sisia ri kala malajah (Andi, 2011:168). Buku ajah kakepah dados kalih inggih punika buku ajah utama ( pokok) lan buku ajah pajangkep (pelengkap). Buku ajah utama madaging peplajahan saking soang-soang widya sane kadadosang buku utama olih guru lan sisia, yening buku ajah pajangkep kadadosang piranti antuk nulungin taler kadadosang wewehan saking buku ajah utama. Kawentenan buku ajah puniki madue tetujon mangda ngwantu sisia ri kala nlatarang materi, ngicenin galah majeng sisia mangda nyumunin utawi malajahin palajahan sane anyar taler ngicenin materi peplajahan sane prasida nudut kayun.

Akeh soroh buku ajah sane wenten ring undagan sekolah sakadi ring undagan SMP/MTs, buku ajah punika kanggen ring soang-soang peplajahan. Silih sinunggilnyane buku ajah sane kanggen ring peplajahan Bahasa Bali inggih punika buku ajah Latansa Aksara Madrasah Tsanawiyah. Buku ajah puniki kakaryanin lan kasusun olih H. Khalid, B.A., dkk., buku sane macihna islami puniki kanggen ring Madrasah Tsanawiyah santukan daging saking buku Latansa Aksara akehan mapaiketan sareng ajahan-ajahan indik islam. Buku sane sampun kasahang olih Bidang Kependidikan Agama Islam lan Pemberdayaan Masjid ring kantor Wilayah Departemen Agama Provinsi Bali niki kanggen nyangkepin piranti pangajahan Bahasa Bali ring sekolah madrasah-madrasah lan lembagalembaga sane wenten ring Bali. Buku ajah Latansa Aksara Madrasah Tsanawiyah puniki madaging materi-materi peplajahan sane marupa wacana, nanging ring wacana buku ajah puniki panilik nyingakin wentennyane kaiwangan-kaiwangan sane 
marupa sasururatan. Kawentenan punika santukan pengawinyane boya ja nelebin indik basa Bali (linier), nika ngawinang pengawinyane nenten tatas uning indik sesuratan inggih punika sesuratan wewehan lan ejaan basa Bali, sakadi sesuratan kruna, wewehan, ceciren pepaosan miwah sane lianan.

Wewehan utawi ring bahasa Indonesia kabaos afiksasi inggih punika morfem sane kaiket sane prasida kabinayang manut genahnyane ring wangun kruna lingga. Wewehan puniki kakepah dados makudang-kudang soroh inggih punika pangater, pangiring, seselan lan wewehan gabungan (Badan Pembina Bahasa, Akasara lan Sastra Bali, 2006:9). Pangater (prefiks) inggih punika wewehan sane wenten ring arep kruna lingga. Pangater ring basa Bali wenten 13, inggih punika N- (anusuara), ma-, ka-, pa-, pi-, sa-, a-, pra-, pari-, pati-, maka-, saka-, kuma-. Pangater pinaka morfem sane kaiket sane prasida kakenain proses morfemis. Proses morfemis inggih punika proses pagentosan suara utawi icalnyane suara utawi fonem, parindikan puniki awinan kacunduknyane morfem siki sareng morfem sane tiosan, sakadi pangater ma-, ma- + ileh dados mileh. Pangiring ring basa Bali wenten kutus, inggih punika -a,-an, -ang, -in, -n, -e, -ing, -ne. Pangiring nenten pacang magentos yening kawewehin ring wangun lingganyane antuk konsonan, nanging yening kawewehin ring wangun lingga sane mapangiring vokal punika ngawinang pacang magentos. Ngenenin indik seselan, seselan inggih punika wewehan ring tengah kruna lingga. Seselan punika akeh ipun patpat, inggih punika um, in, er, el. Seselan nenten pacang kagentosin ri kala ngwangun kruna. Yening wangun lingganyane mawit antuk konsonan lantas molihang seselan, seselan punika kagenahang ring pantaraning konsonan lan vokal sane nyarengin. Yening wangun lingganyane mawit antuk vokal, seselan punika lantas kawewehin ring pangater wangun lingganyane. Taler wenten wewehan sane kagabungang pangater lan pangiringnyane, parindikan punika kawastanin wewehan gabungan (konfiks). Wewehan gabungan ring basa Bali wenten pa-an, ka-an, ma-an, bra-an. Indik wewehan gabungan yening wewehan punika rumeket ring wangun witnyane pastika nganutin silih sinunggil uger-uger pangater lan pangiring.

Kaiwangan siosan sane kacingakin ring sesuratan wacana sane wenten ring buku ajah inggih punika ejaan basa Bali nyane. Ejaan basa Bali puniki mabuat pisan majeng iraga, napi malih jadma sane seneng lan waged ring widang sesuratan. Ejaan basa Bali puniki kanggen titi ri kala iraga nyurat, yening nenten uning indik ejaan basa Bali pastika sesuratan nenten becik lan iwang artin ipun (Tinggen, 1978:1-2). suratan ejaan basa Bali akeh uger-ugernyane, sakadi uger-uger panyuratan huruf kapital, panyuratn huruf sendeh (cetak miring), panyuratan kruna, miwah panyuratan ceciren pepaosan. Sesuratan huruf kapital akeh sane iraga patut uratiang inggih punika ri kala nyurat pangawit lengkara, panyuratan parab, panyuratan wastan wangsa, basa msl. mangda nganggen huruf kapital. Yening ring sesuratan huruf sendeh silih sinunggil uger-ugernyane inggih punika mangda ri kala nyurat ungkapan basa asing sane durung wenten basa Balinyane mangda kacetak miring, upami: balita. Salanturnyane yening nyurat kruna, ri kala nyurat kruna akeh sane patut kauratiang silih sinunggilnyane kruna lingga (kata dasar) lan kruna tiron (kata turunan).

Panyuratan ceciren pepaosan taler akeh sane patut kauratiang sakadi panyuratan tanda titik lan tanda koma. Tanda titik ri kala nyurat wenten ugerugernyane, silih sinunggilyane inggih punika titik kanggen ring ungkur ringkesan wastan gelar, pangkat, jabatan lan nyapa. Yening sesuratan tanda koma, silih sinunggil uger-ugernyane inggih punika tanda koma kanggen ring pantaraning pesengan lan gelar akademik sane nyarengin. Kaiwangan-kaiwangan saking sesuratan punika sumangdane kakelidin, santukan sisia nganggen buku ajah kadadosang sumber sane utama lan rujukan ri kala malajah lan para sisia pastika marasa yening napi sane wenten ring buku ajah nenten madaging kaiwangan-kaiwangan malih utamanyane kaiwangan sesuratan. Kawentenan kaiwangan-kaiwangan punika santukan 
pengawi nenten waged risajeroning widya sesuratan.

Malarapan saking napi sane sampun katelatarang ring ajeng, panilik pacang nglaksanayang tetilikan sane mamurda "Nyelehin Kaiwangan-Kaiwangan Wewehan lan Ejaan Basa Bali ring Wacana Buku Ajah Latansa Aksara Madrasah Tsanawiyah."

Saking pangwedar ring ajeng, bantang pikobet sane prasida kapolihang inggih punika: (1) sapunapi kaiwangankaiwangan wewehan sane wenten ring wacana buku ajah Latansa Aksara Madrasah Tsanawiyah?, (2) sapunapi kaiwangan-kaiwangan ejaan basa Bali sane wenten ring wacana buku ajah Latansa Aksara Madrasah Tsanawiyah?. Saking bantang pikobet sane kawedar ring ajeng, tetujon tetilikan puniki: (1) mangda prasida uning ring kaiwangan-kaiwangan wewehan sane wenten ring wacana buku ajah Latansa Aksara Madrasah Tsanawiyah, (2) Mangda prasida uning ring kaiwangan-kaiwangan ejaan Basa Bali sane wenten ring wacana buku ajah Latansa Aksara Madrasah Tsanawiyah.

Tatilikan puniki madue kawigunan, minakadi kawigunan pamucuk lan kawigunan panglimbak. Kawigunan panglimbak katujuang majeng panilik, majeng sang sane makarya buku ajah, majeng panilik sane siosan.

Sepat siku-siku sane kanggen inggih punika indik: (a) buku ajah, (b) kaiwangan mabasa, (c) wewehan basa Bali, lan (d) ejaan basa Bali. Buku ajah inggih punika buku sane madaging materi peplajahan sane kanggen olih sisia ri kala malajah lan katedunang saking kompetensi dasar sane wenten ring kurikulum sane kasusun kadasarin antuk standar nasional pendidikan. Mohammad (ring Andi, 2011:168) nlatarang buku ajah kakepah dados kalih inggih punika buku ajah utama lan buku ajah pajangkep. Buku ajah utama madaging peplajahan saking soang-soang widya sane kadadosang buku utama sane kanggen olih guru lan sisia. Yening buku ajah pajangkep kadadosang piranti antuk nulungin taler kadadosang wewehan saking buku ajah utama. Manut Andi (2011:169) nlatarang yening tetujon buku ajah puniki, inggih punika: (1) mangda ngwantu sisia ri kala nlatarang materi peplajahan, (2) ngicenin galah majeng sisia mangda nyumunin peplajahan utawi malajahin palajahan sane anyar, (3) ngicenin materi peplajahan sane prasida nudut kayun para sisia.

Kaiwangan mabasa inggih punika ngawigunayang basa lisan miwah sesuratan sane nenten anut ri kala mabebaosan (Setyawati, 2010:15). Sane ngawinang kaiwangan mabasa inggih punika sane kapertama, kirang ngresepang basa sane kaanggen ( Setyawati (2010:15). Kaiwangan puniki sering kabaos kaiwangan intrabahasa. Wenten malih awinan pinih ngamatehang, nenten uning indik pawatesan uger-uger, nglaksanayang uger-uger sane nenten paripurna, miwah iwang menghipotesiskan konsep. Nenten samian sang sane nganggen basa punika dangan ngelingang utawi waged ri kala mabebaosan. Dadosnyane akeh sane iwang mabasa tur nenten anut sareng uger-uger mabebaosan.

Wewehan utawi afiksasi inggih punika morfem sane kaiket sane prasida kabinayang manut genahnyane sane wenten ring wangun kruna lingga. (Pusat Pembinaan dan Pengembangan Bahasa, 1996:32). Manut Badan Pembina Bahasa, Aksara lan Sastra Bali (2006:9-30) wewehan kakepah dados papat inggih punika pangater, pangiring, seselan miwah wewehan gabungan. Pangater ring basa Bali wenten 13, inggih punika $\mathrm{N}$ (anusuara), ma-, ka-, pa-, pi-, sa-, a-, pra-, pari-, pati-, maka-, saka-, kuma-. Pangiring ring basa Bali wenten kutus, inggih punika -a,-an, -ang, -in, -n, -e, -ing, -ne. Seselan punika akeh ipun patpat, inggih punika um, in, er, el. Wewehan gabungan ring basa Bali wenten pa-an, ka-an, ma-an, bra-an.

Mangda sesuratan sane kawedarang prasida becik tur lengut taler prasida karesepang olih pangwacen utamanyane majeng para sisia, nika ngawinang pengawi buku ajah mangda nguratiang uger-uger ring ejaan basa Bali, sakadi sesuratan huruf kapital, panyuratan huruf sendeh, panyuratan kruna lingga, kruna tiron, taler saking ceciren pepaosan (tanda titik, tanda koma, tanda titik dua, tanda hubung msl.). 


\section{KRAMANING TETILIK}

Kramaning Tetilik ketahnyane madaging pidabdab lan tata cara mupulang data ring sajeroning tetilikan. Panilik nglaksanayang pidabdab puniki kanggen nlatarang sapunapi tetilikan puniki kalaksananyang (Wendra, 2014:52).Unteng sane wenten ring kramaning tetilik luir ipiun: (1) pendekatan lan soroh tetilikan, (2) wit data, (3) parikrama mupulang data, (4) data tureksa. Pendekatan lan soroh tetilikan sane kaanggen ring tetilikan puniki inggih punika tetilikan deskriptif kualitatif. Duaning ring tetilik puniki data sane kapolihang utawi kapupulang marupa lengkara sane mawangun kutipan boya ja marupa wilangan. Parindikan punika pateh sakadi sane kabaosang olih Suandi (2008:67) seseleh kramaning deskriptif kualitatif wantah ngicenin predikat marupa babaosan ngenenin variabel sane kaselehin lan nenten kasarengin antuk data statistik. Wit data sane kanggen nyelehin kaiwangan-kaiwangan wewehan lan ejaan basa Bali inggih punika ring wacana-wacana sane wenten ring buku ajah Latansa Aksara Madrasah Tsanawiyah.

$\mathrm{Ri}$ kala mupulang data panilik nganggen kramning dokumentasi. Sukardi (2008:81) maosang kramaning dokumentasi sane kanggen ring tetilik ngawinang panilik molihang gatra saking makudang-kudang sumber sane wenten ring responden utawi ring genah responden nglaksanayang pakaryan sadina-dina. Arikunto (2006:321) maosang kramaning dokumentasi prasida kanggen ngrereh data ngenenin indik hal-hal utawi variabel sane marupa catetan, transkip, buku, surat kabar, majalah, prasasti, notulen rapat, lengger, agenda, miwah sane tioasan. Ring kramaning dokumentasi tetilikan puniki pacang nilikin Wacana Buku Ajah Latansa Aksara Madrasah Tsanawiyah.

Rikala mupulang data panilik nganggen piranti tetilik. Piranti tetilik inggih punika makasami piranti sane kanggen ring sajeroning mupulang data. Manut Wendra (2014:33) piranti tetilik mapaiketan sareng kramaning tetilik sane kanggen ring sajeroning mupulang data.
Piranti sane kanggen ring tetilikan puniki inggih punika kartu data. Kartu data kanggen nyatet data-data sane kapolihang ring tetilikan. Kartu puniki kadagingin identitas manut ring pah-pahan data sane jagi katilikin.

Yening data sane karereh sampun kapupulang salanturnyane panilik pacang nureksain data punika nganggen metode deskriptif kualitatif sane kalaksanayang nganggen petang paletang inggih punika: (1) Nyelehin data/Reduksi Data, data sane kaselehin indik kaiwangan-kaiwangan ring sajeroning wewehan lan ejaan basa Bali ring wacana buku ajah Latansa Aksara Madrasah Tsanawiyah. (2) Nyorohang Data, ndata punika kalaksanayang manut pikobet sane katilikin antuk ngaryanin tabel data. Pikobetnyane inggih punika kaiwangan-kaiwangan sane wenten ring sajeroning wewehan lan ejaan basa Bali ring wacana buku ajah Latansa Aksara Madrasah Tsanawiyah. (3) Pangwedar Data, risampun data punika salanturnyane ngwedar data sane sampun kapolihang. Sumangdane data sane sampun kapolihang punika prasida nyawis pitaken sane wenten ring bantang pikobet landangan karesepin. Ring tetilik puniki sane kawedar inggih punika data sane mapaiketan sareng kaiwangan-kaiwangan ring sajeroning wewehan lan ejaan basa Bali ring wacana buku ajah Latansa Aksara Madrasah Tsanawiyah. (4) Pamicutet, parindikan sane kaping untat ring data tureksa inggih punika pamicutet. Pamicutet inggih punika nyutetang indik pikolih jeroning tetilik sane sane sampun kalaksanayang. Pamicutet ring tetilik puniki indik kaiwangan-kaiwangan sane wenten ring sajeroning wewehan lan ejaan basa Bali ring wacana buku ajah Latansa Aksara Madrasah Tsanawiyah. Pamicutetan puniki pinaka panyawis saking pikobet sane kaunggah ring tetilikan puniki..

\section{PIKOLIH LAN TETEPASAN}

Kaiwangan sesuratan sane wenten ring wacana buku ajah Latansa Aksara Madrasah Tsanawiyah sampun kapupulang nganutin ring pahpahannyane sakadi sampun kaunggahang ring pikolih tetilik. Kaiwangan sane wenten 
ring sajeroning wacana buku ajah Latansa Aksara Madrasah Tsanawiyah punika kaselih manut wewehan lan ejaan basa Bali. Wacana sane wenten ring buku ajah Latansa Aksara Madrasah Tsanawiyah inggih punika wacana sane mamurda: (1) Idul Fitri, (2) Pemerintah Indonesia, (3) Kerta Gosa, (4) Ibadah Shalat, (5) Pasukan Gajah. Kaiwangan-kaiwangan sane wenten ring wewehan ngenenin indik: (1) pengater, (2) wewehan gabungan lan kaiwangan-kaiwangan sane wenten ring ejaan basa Bali ngenenin indik: (1) huruf kapital, (2) huruf sendeh (cetak miring), (3) kruna lingga, (4) kruna tiron, Ian (5) ceciren pepaosan.

Ring pangater kapolihang

kaiwangan: (1) pangater $\mathrm{N}$ - sakadi Ngetiban. Punika kacihnayang ring lengkara Wacana 1 "Ngetiban ring pamuput ngelaksanayang tapaberata puasa Ramadhan, sane makelone asasih, iraga pacang nyambut rahina sane utama tur mautama, inggih pun tanggal siki Syawal, rahina Idul Fitri." (Paragraf 1). Kruna sane iwang ring lengkara punika inggih punika kruna "Ngetiban", wangun krunanyane inggih punika:

Ngetiban N- + atiban dadosne kasurat Ngatiban. Aksara sane magaris beten ring kruna Ngetiban punika mangda kagentosin dados aksara "a" santukan saking wangunnyane panyuratan kruna Ngetiban punika sapatutnyane kasurat Ngatiban. Taler kruna ngetiban puniki boya ja kruna lingga sane marupa kruna lingga awanda. (2) kaiwangan pangater ka-, sakadi: kerahayuan, kerahajengan, msl. Punika kacihnayang ring lengkara Wacana 1 "....taler terus kalaksanayang keajegang, kejejerang, ring lianan bulan puasa, mangda manut ring awig-awig sane sampun kasurat ring AL-Qur'an tur hadith Nabi Muhammad SAW. Usan ngelaksanayang shalat 'Id, sareng sami pada nunas pangampura ma'af soangsoang, mangda dosa-dosa sane sampun pecak klaksanayang, keampunin, karedhaang, mangda polih kerahajengan, kerahayuan sareng sami." (Paragraf 3 ). Kruna sane iwang ring lengkara punika inggih punika kruna keajegang, kejejerang, klaksanayang, keampunin, kerahajengan, kerahayuan. Wangun krunanyane inggih punika: kerahajeng ka- + rahajeng + an dadosne kasurat karahajengan, kerahayuan $\rightarrow$ ka- + rahayu + an dadosne kasurat karahayuan. Krunakruna punika iwang sesuratannyane santukan sesurtannyane nenten manut sareng sesuratan pangater $\mathrm{ka}$ - inggih punika pangater ka- nenten ja magentos yening rumeket ring kruna lingga sane mapurwa antuk wianjana lan pangater kapacang ngwetuang sandi ri kala rumeket ring kruna lingga sane mapurwa antuk suara. (3) Yening saking wewehan gabungan kapolihang kaiwangan marupa wewehan gabungan ka-an, sakadi: kautamaan. Punika kacihnayang ring lengkara Wacana 4 "Shalat berjama'ah inggih ipun shalat sane kalaksanayang sareng-sareng, tur kapucukin olih imam kautamaan shalat fardhu berjama'ah, karmaphalan ipun makeh dados pitulikur, tur becik klaksanayang ring Masjid." (Paragraf 2). Kruna sane iwang sesuratannyane ring lengkara punika kruna "kautamaan", wangun krunannyane inggih punika: kautamaan= ka- + utama + an dadosne kasurat kutaman.

Aksara sane magaris beten ring kruna kautamaan punika mangda kasurat dados kutaman awinan sesuratan wewehan gabungan ka-an ri kala rumeket ring kruna lingga pateh sakadi pangater ka- miwah pangiring -an. Pangater kapacang ngwetuang sandi ri kala rumeket ring kruna lingga sane mapurwa antuk suara taler ring uger-uger pangiring -an sering kanggen ngwetuang sandi suara.

Yening kacingakin pangater ka- ring kruna kautamaan rumeket sareng kruna lingga utama sane mapurwa antuk suara lan pangiring -an punika sering kaanggen ngwetuang sandi dadosne kruna sane iwang punika kasurat kutaman.

Kaiwangan ejaan basa Bali sane wenten: (1) Kaiwangan huruf capital. Saking sesuratan huruf kapital kapolihang kruna sane iwang, sakadi: ring kruna pancasila sane nganggen huruf cenik mangda kagentosin nganggen huruf kapital. Punika kacihnayang ring lengkara "Dasar negarane pancasila, lambang negarane Garuda Pancasila." (Wacana 2, Paragraf 2). Kruna sane iwang inggih punika kruna pancasila. Sesuratan sane patut "Dasar negarane Pancasila, 
lambang negarane Garuda Pancasila." (2) saking sesuratan huruf sendeh kapolihang kaiwangan kruna, sakadi: khutbah, khatib. Kruna punika sumangdane kasurat sendeh santukan ngranjing ring basa tiosang sane durung dados kruna basa Bali. Punika kacihnayang ring lengkara "Daweg Idul Fitri warsa puniki, titiang ngelaksanayang Shalat 'Id, ring alun-alun, pukul pitu semengan. Khatib midartayang ring khutbah ipun indik kautaman rahina Idul Fitri, tur parindikan phalakarma ibadah puasan iragane, mangda amalanamalan sane sampun biasa kalaksanayang, taler terus kalaksanayang keajengang, kejejerang, ring lianan bulan puasa, mangda manut ring awig-awig sane sampun kasurat ring Al-Qur'an tur hadith Nabi Muhammad SAW. Usan ngelaksanayang shalat 'Id, sareng sami pada nunas pangampura ma'af soangsoang, mangda dosa-dosa sane sampun pecak klaksanayang, keampunin, karedhaang, mangda polih kerahajengan, kerahayuan sareng sami." (Wacana 1, Paragraf 3). Kruna sane iwang inggih punika kruna Khatib, pukul, khutbah, puasan, amalan-amalan, terus, bulan, ma'af, karedhaang. Sesuratan sane patut Khatib, pukul, khutbah, puasan, amalanamalan, terus, bulan, ma'af, karedhaang. Lengkara sane madaging kaiwangan kruna punika kasurat "Daweg Idul Fitri warsa puniki, titiang ngelaksanayang Shalat 'Id, ring alun-alun, pukul pitu semengan. Khatib midartayang ring khutbah ipun indik kautaman rahina Idul Fitri, tur parindikan phalakarma ibadah puasa iragane, mangda amalan-amalan sane sampun biasa kalaksanayang, taler terus kalaksanayan,g keajengang, kejejerang, ring lianan bulan puasa, mangda manut ring awig-awig sane sampun kasurat ring Al-Qur'an tur hadith Nabi Muhammad SAW. Usan ngelaksanayang shalat 'Id, sareng sami pada nunas pangampura ma'af soangsoang, mangda dosa-dosa sane sampun pecak klaksanayang, keampunin, karedhaang, mangda polih kerahajengan, kerahayuan sareng sami." (3) saking sesuratan kruna lingga kapolihang kaiwangan, sakadi: karmaphala. Kruna punika sumangdane kasurat unggal santukan ring uger-uger kruna lingga katelatarang kruna lingga punika kasurat tunggal. Punika Kacihnayang ring kruna "Satua-satua inucap suksman ipunindik karmaphala.. Kruna sane iwang inggih punika kruna karmaphala. Sesuratan sane patut karma phala. Lengkara sane madaging kaiwangan kruna punika kasurat "Satua-satua inucap suksman ipunindik karma phala." (4) saking sesuratan kruna tiron kapolihang kaiwangan, sakadi: ngelaksanayang. Sesuratan kruna sekadi sane iwang punika sumangdane kasurat nganutin awig-awig kruna tiron inggih punika pangater ka-, ma-, maka-, kuma-, pra-, pa, lan sa- sane satata kaucap kə-, mə-, makə-, kumə-, prə-, pə-, lan sə- kasurat antuk ka-, ma-, maka-, kuma-, pra-, palan sa-. Punika kacihnayang ring lengkara "Id artin ipun mawali, Fitri artin ipun suci, Idul Fitri artin ipun mawali suci, sekadi rarene wau lekad, metu saking wetenge, tan maduwe dosa." (Wacana 1, Paragraf 2 ). Kruna sane iwang inggih punika kruna sekadi. Sesuratan sane patut sakadi. Lengkara sane madaging kaiwangan kruna punika kasurat "Id artin ipun mawali, Fitri artin ipun suci, Idul Fitri artin ipun mawali suci, sakadi rarene wau lekad, metu saking wetenge, tan maduwe dosa." (5) saking sesuratan ceciren pepaosan kapolihang wentennyan kaiwangan sesuratan tanda titik, tanda koma, tanda titik dual an tanda hubung.

Saking teori sane kanggen inggih punika teori manut Badan Depdiknas (2005) ceciren pepaosan wenten 15 nanging ring buku Latansa Aksara Madrasah Tsanawiyah kaiwangan ceciren pepaosan sane wenten wantah 4 inggih punika wentennyane kaiwangan sesuratan tanda titik, tanda koma, titik dua lan tanda hubung. (1) Tanda Titik, Depdiknas (2005:30) nlatarang titik kanggen ring ungkur ringkesan wastan gelar, pangkat, jabatan lan nyapa. Saking tetilikan sane kalaksanayang ring wacana buku ajah Latansa Aksara Madrasah Tsanawiyah kapolihang wentenyane kaiwangan panyuratan tanda titik sane nenten manut sareng teori inggih punika: "H. Halid. BA" (Wacana 1). Sesuratan sane patut $H$. Halid, B.A. Tanda titik kaanggen ring ungkur ringkesan wastan gelar. (2) Tanda Koma, Depdiknas (2005:33) nlatarang 
tanda koma kanggen ring pantaraning pesengan lan gelar akademik sane nyarengin, kanggen minayang saking ringkesan wangsa utawi marga. Saking tetilikan sane kalaksanayang ring wacana buku ajah Latansa Aksara Madrasah Tsanawiyah kapolihang wentenyane kaiwangan panyuratan tanda koma sane nenten manut sareng teori inggih punika: "...mangda amalan-amalan sane sampun biasa kalaksanayang, taler terus kalaksanayang keajengang, kejejerang, ring lianan bulan puasa, mangda manut ring awig-awig sane sampun kasurat ring AL-Qur'an tur hadith Nabi Muhammad SAW." (Wacana 1, Paragraf 3 ).

Sesuratan sane patut "...mangda amalan-amalan sane sampun biasa kalaksanayang, taler terus kalaksanayang. keajengang, kejejerang, ring lianan bulan puasa, mangda manut ring awig-awig sane sampun kasurat ring Al-Qur'an tur hadith Nabi Muhammad SAW." Kutipan nika ngwentenang indik tanda koma sane nenten kadagingin ring genah sepatutnyane. Tanda koma sane nenten madaging sausan kruna kalaksanayang "...taler terus kalaksanayang keajegang..." nika sane sapatutnyane kadagingin tanda koma. Nika sane ngawinang artin ipun kirang prasida karesepang. (3) Tanda Titik Dua, Depdiknas (2005:35) nlatarang tanda titik dua kanggen ri kala: (1) kanggen penganter ring sajeroning daftar, rangkaian, pemerincian, miwah penunjukan, (2) kanggen pantaraning: (i) jilid utawi nomor lan kaca, (ii) bab taler ayat sajeroning kitab-kitab suci, utawi (iii) murda taler wewidangan murda sajeroning sesuratan, (3) kanggen ring pantaraning pah-pahan sane nyihnayang pamaos miwah sane kabaos ring sajeroning babaosan. Saking tetilikan sane kalaksanayang ring wacana buku ajah Latansa Aksara Madrasah Tsanawiyah kapolihang wentenyane kaiwangan panyuratan tanda titik dua sane nenten manut sareng teori inggih punika:

'Kaiwangan tanda titik dua sane wenten ring wacana buku ajah Latansa Aksara Madrasah Tsanawiyah inggih punika: "Sane nyeneng kepala negarane mawasta : presiden tur kaabih antuk para menterine, sane nyalanang pemerintahane." (Wacana 2, Paragraf 3 ). Sesuratan sane patut "Sane nyeneng kepala negarane mawasta presiden tur kaabih antuk para menterine, sane nyalanang pemerintahane." Kutipan nika ngwentenang indik tanda titik dua sane wenten ring genah sepatutnyane. Tanda titik dua sane iwang genahnyane inggih punika ring pantaraning kruna mawasta lan presiden. Tanda titik dua punika sumangdane kaicalang, tanda titik dua yening kagenahang ring pantaraning kruna mawasta lan presiden punika prasida ngawinang sesuratannyane iwang artin ipun. (4) Tanda Hubung, Depdiknas (2005:36) nlatarang tanda hubung kanggen nyambungang wangun kruna dwi lingga. Saking tetilikan sane kalaksanayang ring wacana buku ajah Latansa Aksara Madrasah Tsanawiyah kapolihang wentenyane kaiwangan panyuratan tanda hubung sane nenten manut sareng teori inggih punika:

"DPR sane ngaryanin undangundang negara nanging tan dados tulak ring undang undang dasar empat limane." (Wacana 2, Paragraf 4 )

Sesuratan sane patut "DPR sane ngaryanin undang-undang negara nanging tan dados tulak ring UndangUndang Dasar empat limane."

Kutipan nika ngwentenang indik tanda hubung sane nenten kadagingin ring genah sepatutnyane. Tanda hubung sane iwang genahnyane ingih punika sapatutnyane kadagingin ring pantaraning kruna undang undang santukan tanda hubung kanggen nyambungang wangun kruna dwi lingga.

Kaiwangan-kaiwangan punika kaselehin nganggen kartu data, akeh kaiwangannyane inggih punika: (1) pengater akehnyane 21 kruna, (2) wewehan gabungan akehnyane 1 kruna, (3) huruf kapital akehnyane 11 kruna, (4) huruf sendeh (cetak miring) akehnyane 63 kruna, (5) kruna lingga akehnyane 14 kruna, (6) kruna tiron akehnyane 8 kruna, lan (7) ceciren pepaosan akehnyane 6 kruna. Dadosne akeh samian sesuratan kruna sane iwang sane wenten ring wacana buku ajah Latansa Aksara Madrasah Tsanawiyah inggih punika 126 kruna. 
PAMUPUT

Ringkesan saking tetilikan puniki inggih punika bantang pikobet saking tetilikan puniki ngenenin indik sapunapi kaiwangan-kaiwangan wewehan sane wenten ring wacana buku ajah Latansa Aksara Madrasah Tsanawiyah lan sapunapi kaiwangan-kaiwangan ejaan basa Bali sane wenten ring wacana buku ajah Latansa Aksara Madrasah Tsanawiyah. Tetilikan puniki madue tetujon mangda prasida uning ring kaiwangan-kaiwangan wewehan sane wenten ring wacana buku ajah Latansa Aksara Madrasah Tsanawiyah lan mangda prasida uning ring kaiwangankaiwangan ejaan basa Bali sane wenten ring wacana buku ajah Latansa Aksara Madrasah Tsanawiyah. Kawigunan tetilikan puniki wentennyane kawigunan pamucuk lan kawigunan panglimbak majeng panilik, majeng sang sane makarya buku ajah, majeng panilik sane siosan.

Tetilikan puniki nganggen teori buku ajah, wewehan basa Bali (teori wewehan sane kanggen saking Badan Pimbina Bahasa, Aksara, lan Sastra Bali) lan teori ejaan basa Bali. Tetilikan puniki pinaka tetilikan deskriptif kualitatif, ring sajeroning mupulang data panilik nganggen kramaning dokumentasi lan ri kala mupulang data piranti sane kanggen inggih punika kartu data. Pikolih sane kapolihang saking tetilikan puniki inggih punika wentennyane kaiwangan wewehan sane marupa kaiwangan pangater lan wewehan gabungan, taler kaiwangan ejaan basa Bali sane marupa kaiwangan sesuratan huruf kapital, huruf sendeh, kruna lingga, kruna tiron, lan ceciren pepaosan.

Kaiwangan-kaiwangan wewehan sane wenten ring wacana buku ajah Latansa Aksara Madrasah Tsanawiyah inggih punika: (1) pangater, kaiwangan pangater sane wenten ring buku ajah Latansa Aksara Madrasah Tsanawiyah inggih punika kaiwangan pangater $\mathrm{N}$-, kaiwangan pangater ka-, (2) wewehan gabungan, kaiwangan wewehan gabungan sane wenten ring wacana buku ajah Latansa Aksara Madrasah
Tsanawiyah inggih punika kaiwangan wewehan gabungan ka-an.

Kaiwangan-kaiwangan ejaan basa Bali sane wenten ring buku ajah Latansa Aksara Madrasah Tsanawiyah inggih punika: (1) sesuratan huruf kapital , (2) sesuratan huruf sendeh, (3) sesuratan kruna lingga, (4) sesuratan kruna tiron, Ian (5) sesuratan ceciren pepaosan sane marupa kaiwangan tanda titik, tanda koma, tanda titik dua miwah tanda hubung. Kaiwangan ejaan basa Bali pinih akeh kacingakin ring kaiwangan panyuratan huruf sendeh.

Manut ring tetilakan sane sampun kalaksanayang lan pikolih tetilkan sane sampun kapolihang. Panilik jagi nguningayang piteket-piteketnyane. Piteket-piteket punika mapaiketan sareng kawigunan tetilik inggih punika piteket pamucuk lan piteket panglimbak. Piteket pamucuk mangda prasida kanggen paweweh pangajahan ri kala nyurat wewehan lan ejaan basa Bali taler prasida ngamecikang pendidikan utamannyane risajeroning makarya buku ajah utamanyane buku ajah basa Bali. Taler piteket panglimbaknyane majeng panilik mangda prasida kanggen rikala panilik pacang makarya buku ajah, nika ngawinang panilik sampun uning nyurat wewehan lan ejaan basa Bali sane patut. Majeng sang sane makarya buku ajah mangda kanggen ngamecikang buku ajah sane kakaryanin taler sang sane makarya buku ajah prasida uning indik sesuratan wewehan lan ejaan basa Bali sane patut. Sane pinih untat majeng panilik sane siosan mangda prasida kanggen nulungin panilik sane sioasan ri kala nglaksanayang tetilikan asoroh.

\section{KAPUSTAKAAN}

Arikunto, Suharsimi. 2006. Prosedur Penelitian Suatu Pendekatan Praktek. Jakarta: Rineka Cipta.

Badan Pembina Bahasa, Aksara lan Sastra Bali. 2006. Tata Basa Bali. Denpasar: Balai Penelitian Bahasa.

Departemen Pendidikan Nasional. 2005. Pedoman Umum Ejaan Bahasa 
Bali dengan Huruf Latin. Denpasar: Balai Bahasa.

Prastowo, Andi. 2011. Panduan Kreatif Membuat Bahan Ajar Inovatif: Menciptakan Metode Pembelajaran yang Menarik dan Mengesankan. Jogjakarta: DIVA Press.

Prayuda, I Putu Eka. 2013. Analisis Kesalahan Penulisan Prefiks dalam

Pusat Pembinaan dan Pengembangan Bahasa. 1996. Tata Bahasa Baku Bahasa Bali. Denpasar: Balai Penelitian Bahasa.
Suandi, I Nengah. 2008. Pengantar Metodelogi Penelitian Bahasa. Singaraja: Undiksha.

Sukardi. 2008. Metodelogi Penelitian Pendidikan. Jakarta: PT Bumi Akasara.

Tinggen, I Nengah.1978. Ejaan Bali Yang Disempurnakan. Denpasar: Dinas Pangajaran Daerah Tingkat I Bali.

Wendra, I Wayan. 2014. Buku Ajar Penulisan Karya IImiah. Singaraja: Undiksha.

Setyawati, Nanik. 2010. Analisis Kesalahan Berbahasa Indonesia: Teori dan Praktik. Surakarta: Yuma Pustaka. 